\title{
Nitrate Uptake Affects Cell Wall Synthesis and Modeling
}

\author{
Simone Landi and Sergio Esposito* \\ Dipartimento di Biologia, Università degli Studi di Napoli Federico II, Complesso Universitario di Monte Sant'Angelo, \\ Napoli, Italy
}

Nowadays, the relationship(s) about $\mathrm{N}$ assimilation and cell wall remodeling in plants remains generally unclear. Enzymes involved in cell wall synthesis/modification, and nitrogen transporters play a critical role in plant growth, differentiation, and response to external stimuli. In this review, a co-expression analysis of nitrate and ammonium transporters of Arabidopsis thaliana was performed in order to explore the functional connection of these proteins with cell-wall related enzymes. This approach highlighted a strict relationship between inorganic nitrogen transporters and cell wall formation, identifying a number of co-expressed remodeling enzymes. The enzymes involved in pectin and xyloglucan synthesis resulted particularly co-regulated together with nitrate carriers, suggesting a connection between nitrate assimilation and cell wall growth regulation. Major Facilitator Carriers, and one chloride channel, are similarly co-expressed with pectin lyase, pectinacetylesterase, and cellulose synthase. Contrarily, ammonium transporters show little or no connection with those genes involved in cell wall synthesis. Different aspects related to plant development, embryogenesis, and abiotic stress response will be discussed, given the importance in plant growth of cell wall synthesis and nitrate uptake. Intriguingly, the improvement of abiotic stress tolerance in crops concerns both these processes indicating the importance in sensing the environmental constraints and mediating a response. These evaluations could help to identify candidate genes for breeding purposes.

Keywords: abiotic stress, Arabidopsis, ammonium, tomato, xyloglucane synthesis, pectin synthesis, cellulose synthesis, nitrogen assimilation

\section{INTRODUCTION}

Cell wall development and remodeling are crucial processes for plants. The molecular and biochemical modifications of cell wall play critical roles in various aspects of plant physiology such as, differentiation, senescence, abscission, plant-pathogen interactions, abiotic stress response, plant growth, and others (Marowa et al., 2016). Cell wall is a necessary plant characteristic, mainly composed by polysaccharides, such as, cellulose and hemicellulose; pectins; lignin, and structural proteins (Guerriero et al., 2014, 2016). A major feature of the cell wall is its dynamic and active structure, remodeled during key stages of development, and in response to external stimuli. Therefore, during the plants life there is an incessant assembly, disassembly, and re-arrangement of the cell wall (Marowa et al., 2016). These processes are critical for plant development and acclimation, because the cell wall loosening is a direct cause of cells expansion and plant growth (Fukuda, 2014). 
An interesting example is the cell wall remodeling during the stress response, by the activation of a wide range of enzymes involved in cell wall loosening (Tenhaken, 2015). This regulation represents a crucial point for tolerance to drought and salinity in crops (e.g., tomato; rice), when huge number of genes was differentially expressed upon stress (Iovieno et al., 2011; Landi et al., 2017b). Furthermore, cell wall is differently modified by biotic stress and pathogen attacks, revealing its functional plasticity (Bellincampi et al., 2014).

Among the mechanic modifications required for cell wall remodeling, the enzymes mainly involved include xiloglucan endotransglucosylase/hydrolase, expansine, enzymes involved in pectin modification (e.g., pectinesterase; pectin lyase), peroxidase (Tenhaken, 2015; Franciosini et al., 2017; Landi et al., 2017b). These enzymes are consistently regulated during nutrient deficiency (as nitrogen and/or sulfur deprivation), in order to allow the correct uptake of these elements (Fernandes et al., 2013). Particularly, $\mathrm{N}$ deficiency induces cell wall loosening: $\mathrm{N}$ is mainly assimilated in plants as nitrate $\left(\mathrm{NO}_{3}^{-}\right)$by specific transporters (Fan et al., 2017). This family includes a number of carriers generally described as low or high affinity transporters, playing different roles depending on the soil availability of $\mathrm{N}$. In addition, plants can assimilate $\mathrm{N}$ as ammonium $\left(\mathrm{NH}_{4}^{+}\right)$by specific channels (Glass et al., 2002).

In the present study, an overview of the relationship between cell wall remodeling and nitrogen uptake will be provided. The co-expression analysis of Arabidopsis thaliana nitrate and ammonium transporters will be explored, in order to identify how cell wall enzymes relate to $\mathrm{N}$ assimilation, and clarify the concurrent processes involved in cell wall re-organization. A final survey with a perspective on the importance of $\mathrm{N}$ assimilation and cell wall modification upon abiotic stress will be given.

\section{N UPTAKE AND CELL WALL REMODELING: A CO-EXPRESSION ANALYSIS}

The relationships between $\mathrm{N}$ accumulation and plant cell wall remodeling are argument of debate. The molecular cross-interactions between these processes are still unclear: therefore, nitrogen and ammonium transporters were identified in A. thaliana, and co-expression analysis was made using the ATTED-II software version 8.0 at http://atted.jp (Aoki et al., 2016).

In detail, six low affinity nitrate transporters (At1g12110, Atlg69850, Atlg32450, Atlg27080, Atlg69870, At4g21680), two "major facilitator super family" proteins (At1g52190, At3g16180), seven high affinity nitrate transporters (At1g08090, Atlg08100, At5g60780, At5g60770, At1g12940, At3g45060, At5g14570), and six ammonium transporters (At4g13510, At1g64780, At1g64780, At4g28700, At3g24290, At2g38290) were selected at this purpose.

The chloride channel A (CLCA-At5g40890) was chosen based on its capability of $2 \mathrm{NO}_{3}^{-} / 1 \mathrm{H}^{+}$exchange.
It should be noted that ammonium transporter 1.3 (AMT1.3-At1g64780); and 1.5 (AMT1.5-At3g24290) showed no co-expression in the database utilized, and thus these carriers were excluded in the present analysis.

Intriguingly, several cell wall related genes are co-expressed with nitrate and ammonium transporters (Table 1). Particularly, it is worth noting the presence of a number of enzymes involved in cell wall loosening: during nitrogen assimilation, a disassembly of the cell wall could be necessary for an enhanced $\mathrm{N}$ uptake, allowing a correct cell and plant growth. Furthermore, this behavior suggests that a right balance of cell wall loosening and thickening is desirable during plant growth, in order to correctly supply nutrients for biosynthesis of both primary and secondary cell walls. This balance could be enhanced by adequate nitrogen assimilation.

Consistent with these considerations, Fernandes et al. (2016) showed a diversified molecular expression of the cell wall loosening related genes in Vitis viniferae callus subjected to nitrogen, sulfur, and phosphorus deficiency, highlighting that $\mathrm{N}$ affects the cell wall responses more severely than other nutrients.

As shown in Table 1, low affinity and high affinity nitrate transporters showed similar number and type of cell wall related co-expressed genes. Otherwise, ammonium transporters showed a lower co-expression with cell wall related genes; this would probably suggest minor, or absent relationship(s) with cell wall remodeling.

Examples of cell wall remodeling genes which appear related to nitrogen transport are pectinase, involved in pectin degradation, such pectin lyase (At4g23820, At3g07010, At3g16850, At5g48900, At5g14650, At3g57790, At3g16850), pectinacetylesterase (At1g09550, At5g23870), or pectin methylesterase (At3g14310). Particularly, the cleavage of homogalacturonans by pectinesterases produces substrates for polygalacturonase and pectin lyase, acting in the cleavage of the polygalacturonic acid (Sun and Nocker, 2010).

These genes are important members of fruits' maturation network (Marín-Rodríguez et al., 2002), and previous studies described their involvement in the abiotic stress response (Hong et al., 2010; Tenhaken, 2015; Landi et al., 2017b). It has been proposed that pectins are able to form gel structures that increase cell wall consistency (Fernandes et al., 2016).

The activation of pectinase(s) together with nitrogen transporters could induce the relaxation of the cell wall.

Other important actions associated with nitrogen uptake are the modification of xyloglucans. A number of enzymes involved in this process were co-expressed with nitrate transporter such xyloglucan-endotransglucosylases/hydrolases (XTH-e.g., At3g44990, At3g48580, At2g06850), xyloglucanendo/transglycosilase (XTR-e.g., At4g25810), and expansins (e.g., At1g20190-At2g40610). Xyloglucans are the major hemicellulosic polymers of dicot plants, playing a critical role in cellulose fibrils connection. Modification in their content is an important process regulating several physiological plant responses by the cell wall remodeling (Tenhaken, 2015; Marowa et al., 2016). It was proposed that xyloglucan regulation by expansins could improve the efficiency of nutrient uptake. In fact, several types of expansins respond to different nutrient 


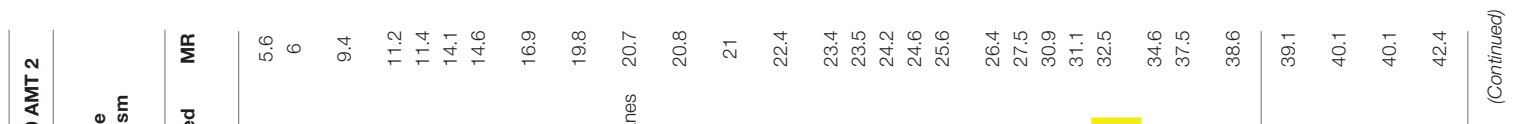

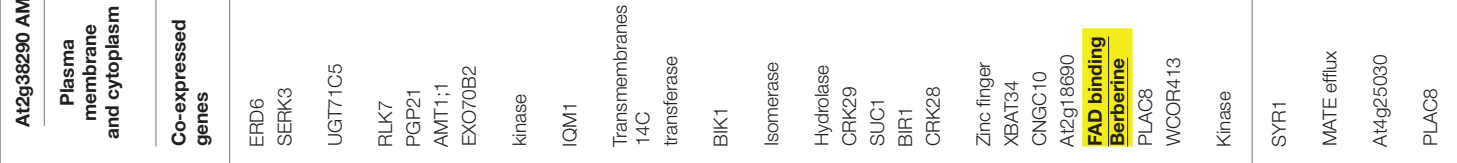

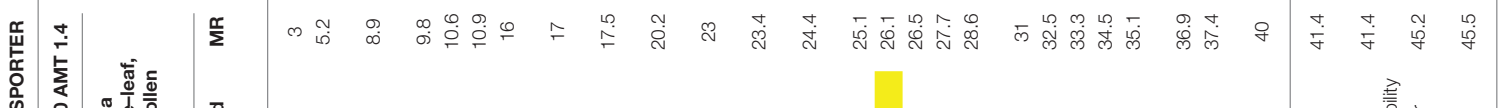

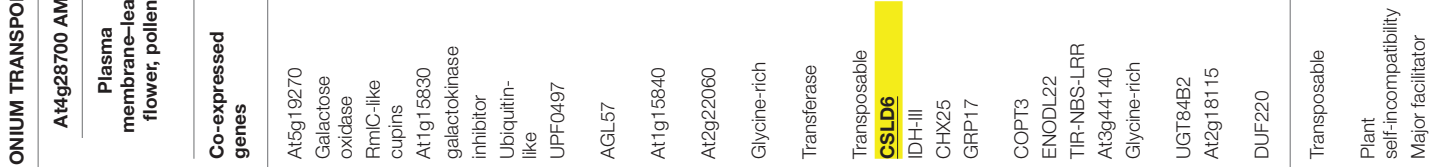

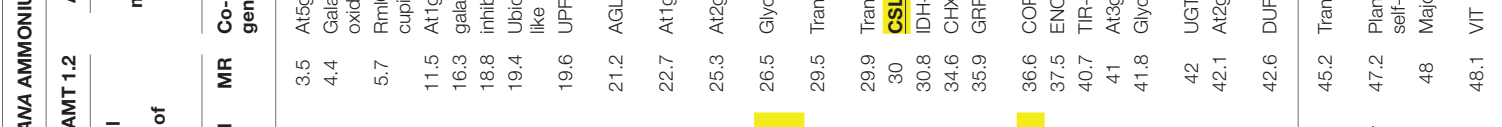

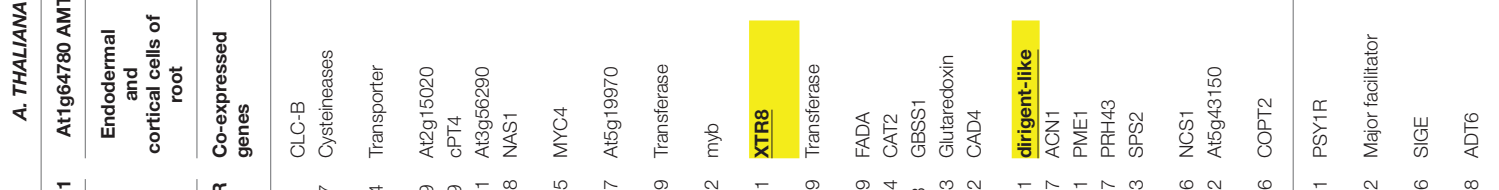

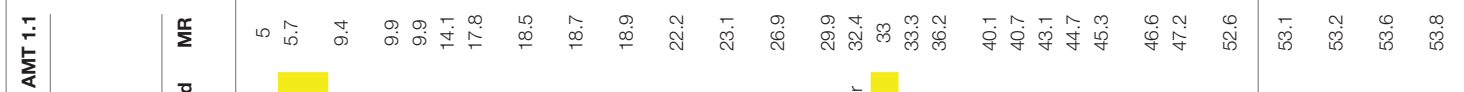

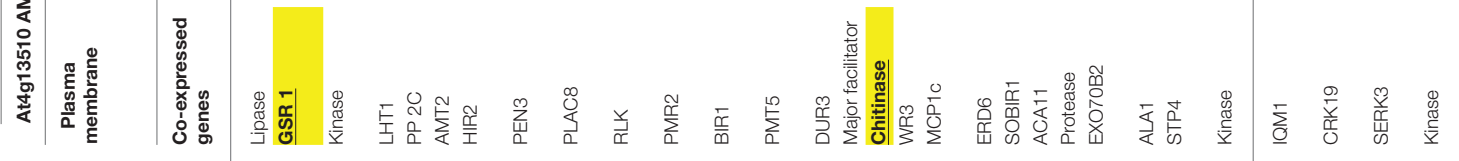

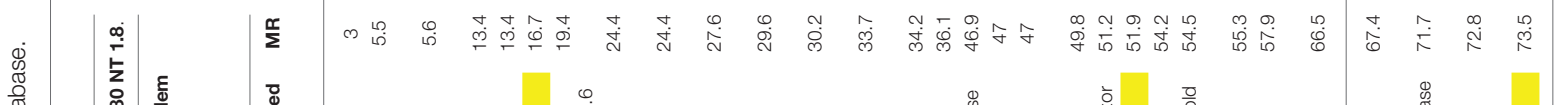

要

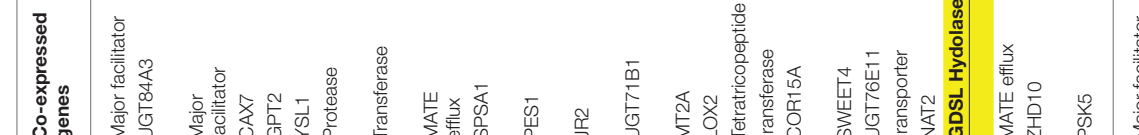

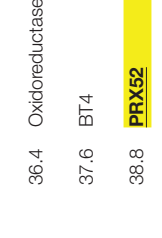

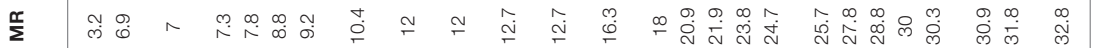

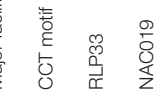




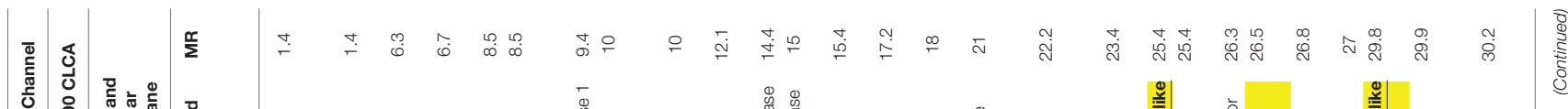

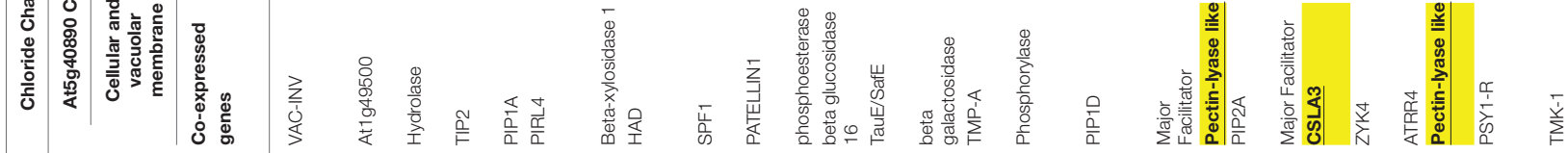

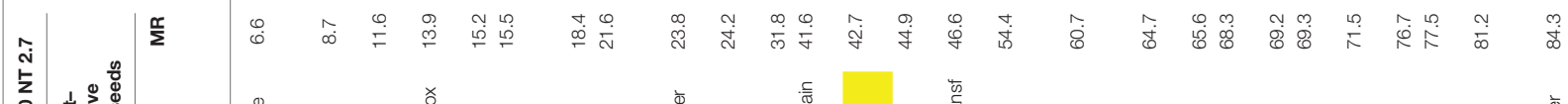

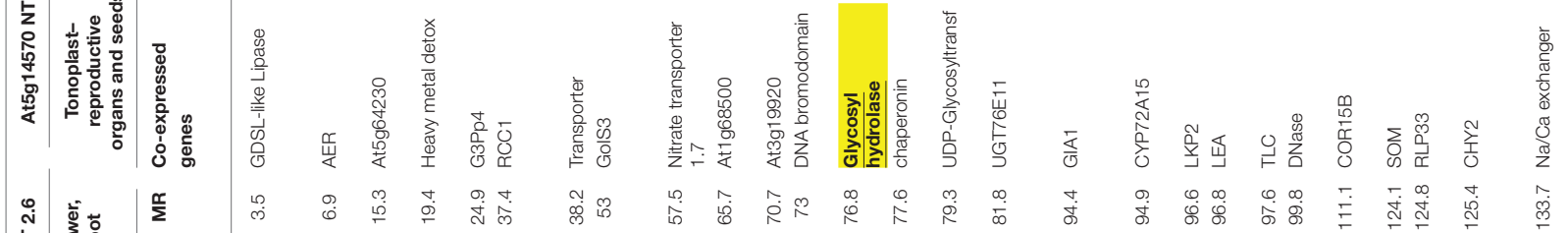

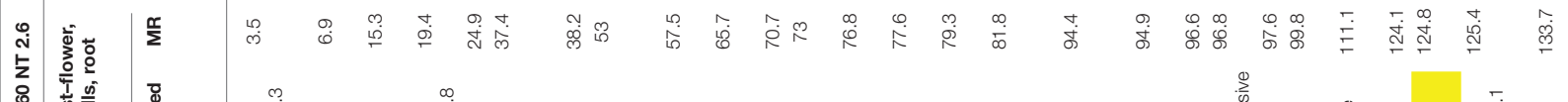

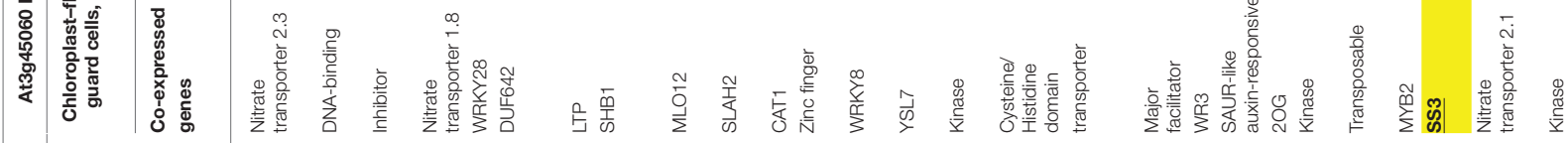

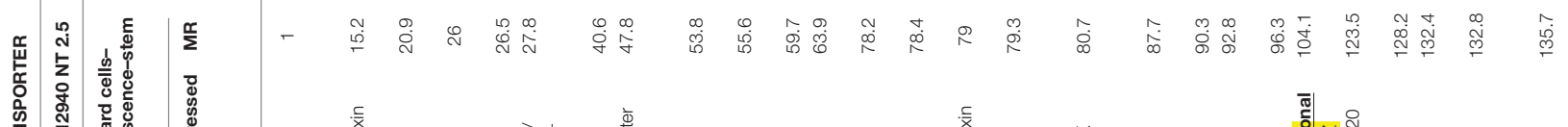

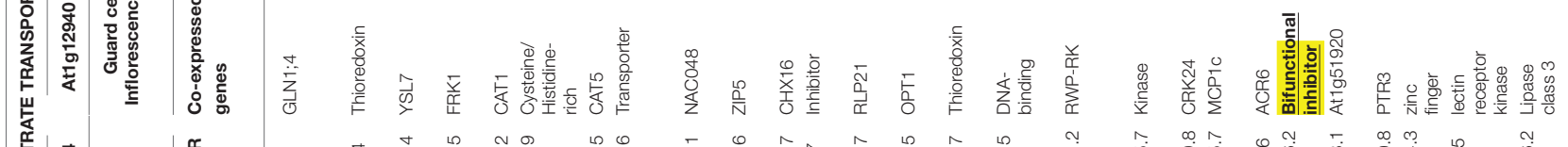

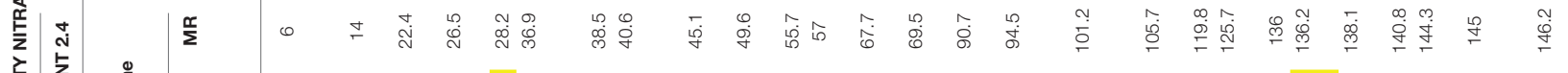

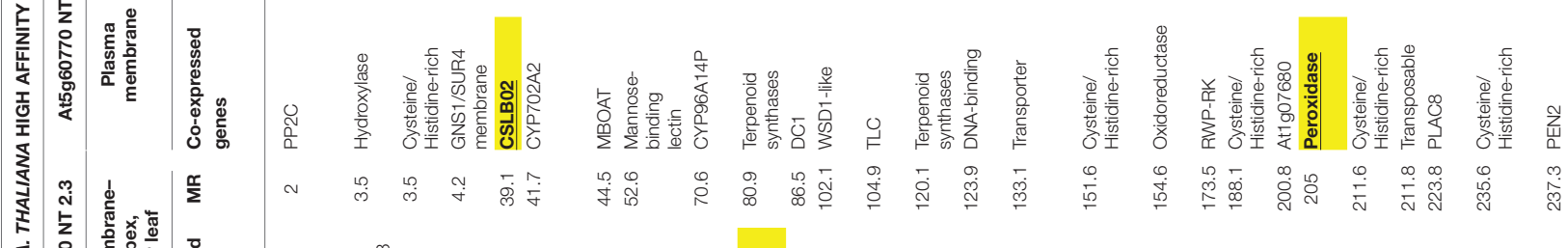

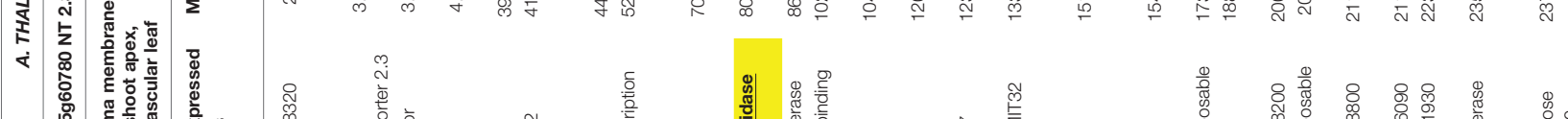

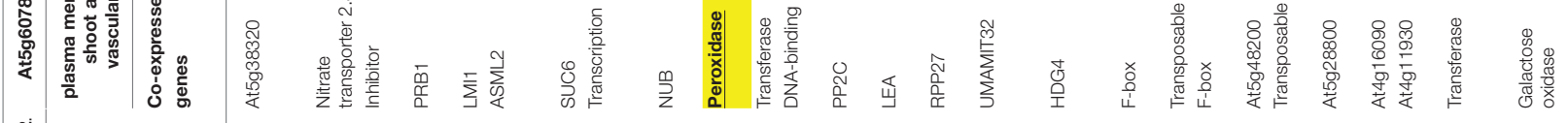

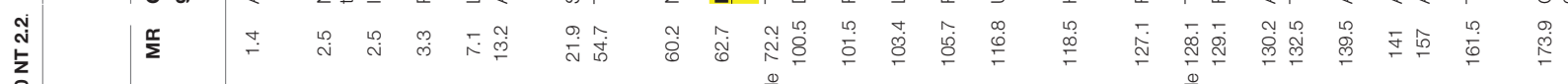

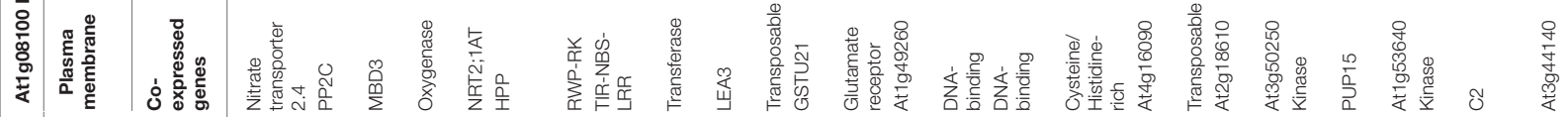

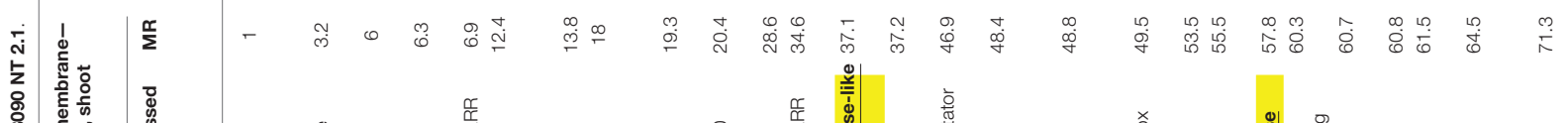

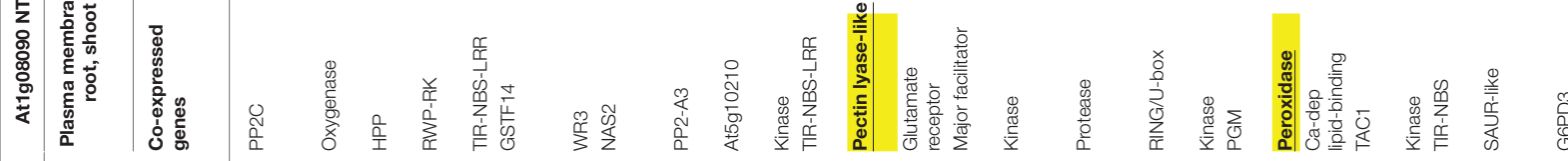

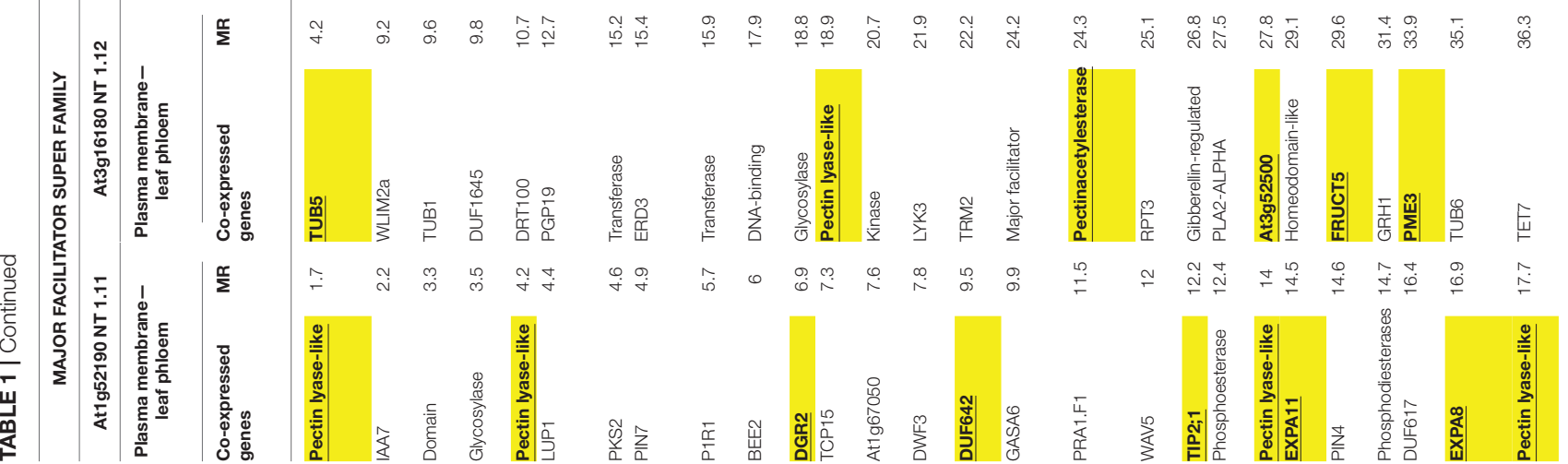




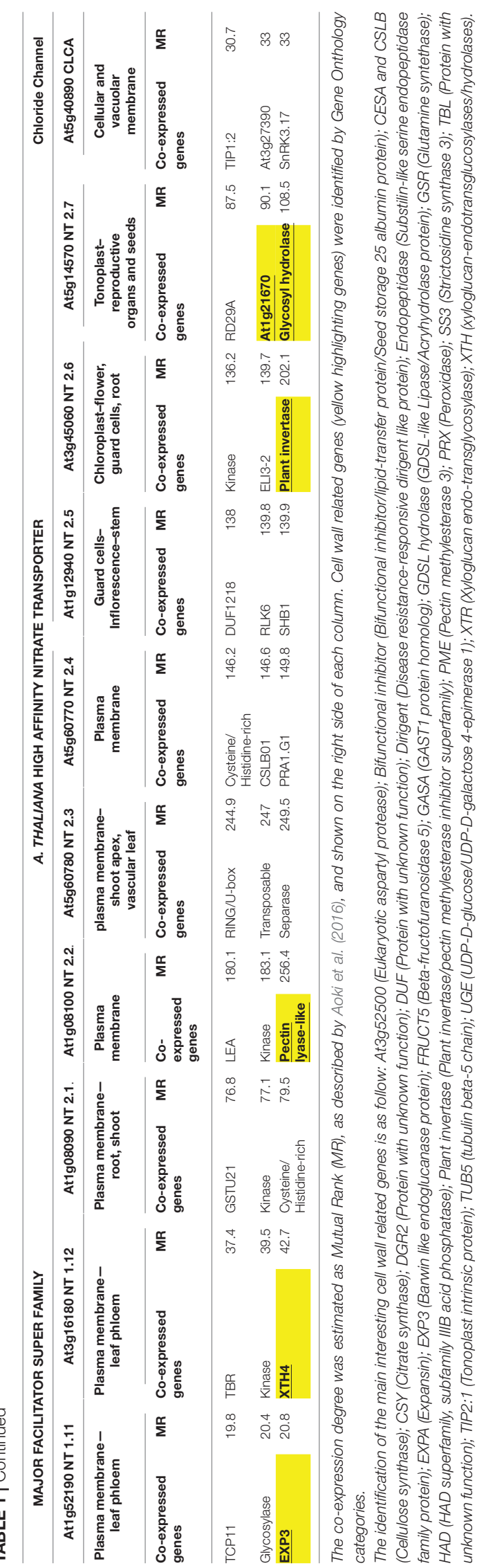

deficiencies including nitrogen, phosphorus, potassium, and iron ones (Li et al., 2014).

Furthermore, expansins have been proved to play a pivotal role in several aspects such fruit ripening and softening, abiotic stress tolerance, and crops yield (Zhou et al., 2014; Minoia et al., 2015; Marowa et al., 2016).

Interestingly, the major facilitator superfamily genes Atlg52190-AtNT 1.11 and At3g16180-AtNT1.12 are consistently co-expressed together with several cell wall relaxation genes; it must be underlined that these transporters play an important role in plant physiology translocating nitrate from phloem to xylem.

Particularly, their action appears critical for high-nitrateenhanced shoot growth, and for nitrate translocation from old to young leaves. These processes represent key points affecting biomass production, and crop yield (Hsu and Tsay, 2013).

Finally, nitrate transporter and cell wall related processes are connected also during embryogenesis. The AtNRT1.6 is expressed in reproductive tissues, namely vascular tissue of the silique and funiculus. This transporter plays a critical role during early embryogenesis phase (Almagro et al., 2008): interestingly, this gene was co-expressed with cellulose synthase A (CESAAt2g25540). Previous studies reported that several members of this family are necessary for a correct embryogenesis (Beeckman et al., 2002; Goubet et al., 2003). This evidence corroborated the idea of a strict connection between nitrogen uptake and cell wall regulation in various aspects of plant development and morphogenesis.

\section{THE RELATIONSHIP BETWEEN NITROGEN TRANSPORTER AND CELL WALL UPON ABIOTIC STRESS}

It is worth to point out that both nitrate transporters and cell wall remodeling enzymes play crucial roles in response to various abiotic stresses (Tenhaken, 2015; Fernandes et al., 2016; Fan et al., 2017; Landi et al., 2017b).

Among nitrate transporters, AtNRT1.1 (At1g12110) was identified as a salt and drought stress responsive gene (Guo et al., 2003; Álvarez-Aragón and Rodríguez-Navarro, 2017). This gene is expressed in guard cells and plays an important role in stomata opening: AtNRT1.1. mutants showed an enhanced drought tolerance (Guo et al., 2003).

Further, AtNRT.1.1 plays a major role in $\mathrm{Na}^{+}$and $\mathrm{Cl}^{-}$ assimilation in both normal and high salinity conditions, suggesting its role in salt stress tolerance (Álvarez-Aragón and Rodríguez-Navarro, 2017). Interestingly, co-expression analysis showed this gene less co-expressed with cell wall related genes (Table 1): this confirms that cell wall remodeling genes were diversely down-regulated during abiotic stress in order to limit the damage (Leucci et al., 2008). Intriguingly, AtNRT1.1. showed a number of stress-related coexpressed genes such as, tonoplast intrinsic protein (TIPs-At4g17340), glucose-6P dehydrogenase (G6PDH-At5g13110), heat shock proteins (HSP-At5g02480), late embryogenesis proteins (LEA-At3g52470; Boursiac et al., 2005; Ma et al., 2006; Basile et al., 2011; Esposito, 2016; Landi 
et al., 2017a), thus highlighting its role in abiotic stress response (Table 1).

Another interesting nitrate transporter involved in abiotic stress response is AtNRT1.8 (At4g21680): cadmium $\left(\mathrm{Cd}^{++}\right)$ stress strongly stimulated the accumulation of this transporter in roots, and A. thaliana plants with mutated AtNRT1.8 showed increased sensibility to $\mathrm{Cd}^{++}$stress (Gojon and Gaymard, 2010). Intriguingly, as showed in Table 1, AtNRT1.8 is coexpressed with a number of cell wall related genes, namely XTH11 (xyloglucan-endotransglucosylases/hydrolases), XTR6 (xyloglucan-endo/transglycosilase), and PRX52 (peroxidase superfamily). Particularly, peroxidase activity was assisted by a number of antioxidant enzymes such as, glutathione S-transferase (GSTU4), NAD(P)-linked oxidoreductase (AKR4C8), and others (Table 1). This could be necessary to regulate the increased of reactive oxygen species (e.g., $\mathrm{H}_{2} \mathrm{O}_{2}$ ), enhancing the mechanical stability of the cell wall, and thus stress tolerance (Tenhaken, 2015).

Further, CLCA (At5g40890) is a chloride channel that plays a role as $\mathrm{NO}_{3}^{-} / \mathrm{H}^{+}$exchanger, useful to accumulate nitrate in vacuoles (De Angeli et al., 2006). Recently, this transporter was reported as related to $P P 2 A-C 5$ (At1g69960) during salt stress response (Hu et al., 2017); the co-expression analysis showed a relationship with cell wall related proteins such as, pectin lyase (At3g57790 and At3g16850); cellulose synthase C; and with aquaporines such TIPs (tonoplast intrinsic proteins) and PIPs (Plasma membrane intrinsic proteins). The co-expression of TIP2 (At3g26520) and TIP2.1 (At3g16240) confirms the critical role of CLCA in nitrate translocation into the vacuoles as well. Interestingly, NTR1.1 is co-expressed with tonoplast intrinsic protein TIP2.2 (At4g17340). Particularly, nitrate allocation from/to vacuoles suggested a central role during plant adaption in $\mathrm{N}$-rich and $\mathrm{N}$-deficient environments (Fan et al., 2017). Recent evidence indicated the role of phosphatidylinositol-3,5-bisphosphate as signal for nitrate translocation in vacuoles by the activation of CLCA (Carpaneto et al., 2017).

Further, the regulation of the nitrate allocation into the vacuoles was assisted by peptide transporters (PTRs), such as, AtPTR4 (At2g02020) and AtPTR6 (At1g62200); these proteins showed vacuole specific localization, thus playing a role in nitrate storage in the plant cell (Weichert et al., 2012). Fan et al. (2017) reported that NRT2.1 plays an important role in resistance to drought. This action was reported in different species such as, Arabidopsis and Brassica, together with NRT1.1 and NRT1.5 (Goel and Singh, 2015; Fan et al., 2017). Other authors reported that NRT2.1 regulated root hydraulic conductivity, by altering $\mathrm{NO}_{3}^{-}$accumulation (Li et al., 2016). Furthermore, this nitrate transporter positively regulates the translational levels of PIPs; the bioinformatic analysis highlights the co-expression of this transporter with cell wall related genes, such pectin lyase and peroxidase; and with abiotic stress related genes such protein phosphatase $2 \mathrm{C}(P P 2 C)$, glutathione S-transferase (GST), G6PDH, and others, thus confirming that nitrogen transporters, cell wall remodeling enzymes, and others genes together contributes for abiotic stress tolerance.

\section{TRANSCRIPTOMIC MODIFICATION IN ADVERSE ENVIRONMENT: NITRATE AND CELL WALL CANDIDATES GENES FOR TOLERANCE IN CROPS}

Nowadays, next generation sequencing (NGS) provides for new insight into crops genetic breeding, generating huge amount of data, mapping across crops population, and discovering useful genes, QTL and genomic traits (Cobb et al., 2013).

The improvement of tolerance in crops vs. abiotic stress remains today an important focus for plant biology researchers because this reduces plant growth, development, and productivity (Reynolds and Tuberosa, 2008; Cardi et al., 2015; Ruggiero et al., 2017). This promising strategy can be prosecuted by applying modern molecular and -omics techniques, together with the study and the analysis of traditional landraces (Van Oosten et al., 2016; Landi et al., 2017a,b). In the last years, many researchers investigated this topic using NGS; in tomato (Solanum lycopersicum), 966 differential expressed genes (DEGs) have been identified upon drought; among these, at least 50 genes involved in cell wall remodeling and nitrate transport were identified. Particularly, 20 clusters of genes were grouped, and their transcripts show similar expression trends (Iovieno et al., 2011).

Some clusters showed interesting correlations: in cluster 4, expansin (Solyc06g049050), nitrate transporter (Solyc12g006050), cellulose synthase (Solyc04g071650), and XTH (Solyc02g091920); in cluster 5, cellulose synthase (Solyc04g077470), expansin (Solyc02g088100), nitrate transporter (Solyc03g113250), and XTH (Solyc07g052980).

Similarly to other abiotic stress, nutrient deprivation negatively influences crops yield. Nitrogen deficiency is a critical cause of yield loss, but $\mathrm{N}$ fertilizer consumption has become one of the major costs of crop production (Zhao et al., 2015).

A huge transcriptomic modification in durum wheat (Triticum turgidum) upon nitrogen starvation highlighted 4,626 DEGs in different organs such as, roots, leaves, stems, and spikes (Curci et al., 2017). An interesting enrichment of GO categories related to "Cell Wall Biogenesis" and "Cellulose metabolism" in leaves was reported, highlighting the relationship between nitrogen nutrition and regulation of the integrity of cell wall. Also, a number of up-regulated high affinity nitrate transporters in root and flag leaf (e.g., NT2.3 and NT2.5) were found, while numerous cell wall related genes showing a transcriptional regulation induced by nitrogen starvation. Examples of these are pectin lyase, expansin, and wall associated kinase (WAK). Particularly, WAKs play critical roles in root growth under $\mathrm{N}$ limitation (Kiba and Krapp, 2016). Intriguingly, the correlation among WAKs and nitrogen deficiency was also observed in two lines of Tibetan barley (Hordeum vulgare) expressing nitrogen transporter with genomic variants (Quan et al., 2016).

Moreover, nitrogen starvation was studied in rice (Oryza sativa; Yang et al., 2015). This stress induced the modification in the expression of 1,158 genes in leaves, and 492 in roots. Part of these were identified as cell wall related genes: in roots it has been reported the expression of few genes involved 
in cell wall degradation, such fasciclin-like arabinogalactan protein (Os10t0524300), and sulfated surface glycoprotein (Os10t0524300). On the contrary, in leaves a higher number of DEGs related to various aspects of cell wall regulation was reported, such fasciclin-like arabinogalactan protein (Os01t0668100), beta-galactosidase (Os06t0573600), UDPglucuronic acid decarboxylase (Os03t0278000), and expansin (Os10t0555900, Os10t0556100).

Recently, Zhao et al. (2015) reported interesting results about the response of cucumber (Cucumis sativus) at early nitrogen shortage. Among the top enriched GO categories, the presence of genes encoding for proteins and enzymes involved in xyloglucan transferase activity were reported, underlining their role(s) in cell wall synthesis and remodeling. Further, a number of genes involved in cell wall loosening, cell expansion or cell wall component synthesis, including pectin lyases (Csa1G049960), XTH (Csa1G188680), pectinesterases (Csa7G447990; Csa7G343850), and expansin (Csa5G517210) were grouped in different expression clusters, and regulated during the early stage of $\mathrm{N}$ deficiency response. Thus, pectins breakdown under $\mathrm{N}$ deficiency would provide substrates to other biological processes, compensating for the depressed photosynthetic carbon assimilation. In addition, a connection between cell wall degradation and ascorbic acid metabolism can be hypothesized, in order to provide an improvement of fruit quality upon $\mathrm{N}$ deficiency (Zhao et al., 2015).

Interestingly, cell wall related and nitrate transporter genes interact also during heavy metal stress such as, aluminum excess ( $\mathrm{Li}$ et al., 2017). It has been reported a critical role for the STOP1/ART1, a zinc finger transcription factor, which induced the expression of a number of genes related to the aluminum toxicity tolerance in crops (Yamaji et al., 2009).

The effectors of STOP1/ART1 suggest a correlation in tea plants (Camelia sinensis) among cell wall related enzymes (e.g., expansine and polygalacturonase); membrane proteins (e.g., magnesium transporter, UDP-glucosyl transferase, and potassium transporter); detoxification proteins (e.g., Heat shock protein 20) and nitrate transporters. Therefore, a major role in the aluminum allocation for tolerance, or accumulation, has been proposed for this protein network (Li et al., 2017). A schematic summary, describing the key events during drought, salt and $\mathrm{N}$ starvation responses, and their relationships between nitrogen uptake and cell wall remodeling, is proposed in Figure 1.

\section{CONCLUSIONS}

This review provided for an updated survey between the correlation of nitrogen assimilation and cell wall related genes. These genes contribute together in several aspects of plant growth, physiology, and response to external stimuli. Evidences here described strongly support the notion of an involvement of NT and cell wall remodeling genes (e.g., pectin lyase, XTH, expansin) as a part of complex machinery involved in abiotic stress response in crops.

Further, cell wall related genes play a role in $\mathrm{N}$ starvation inducing cell wall relaxation and helping $\mathrm{N}$ assimilation.

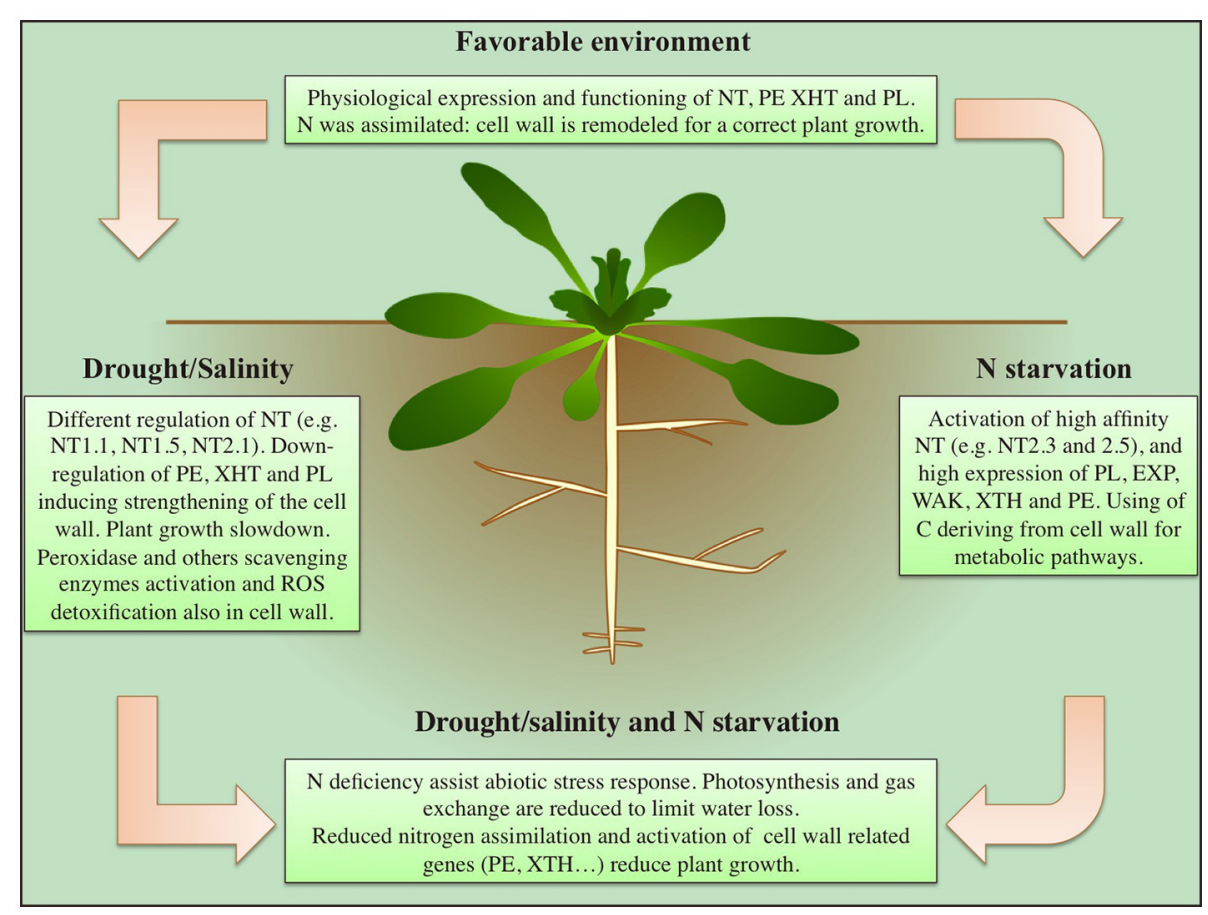

FIGURE 1 | Main effects induced by drought, salinity and nitrogen starvation on nitrogen assimilation and cell wall remodeling in plants. 
Therefore, these gene families could represent promising traits for genetic improvement in abiotic stress tolerance.

\section{AUTHOR CONTRIBUTIONS}

SL and SE conceived the idea and wrote the manuscript.

\section{REFERENCES}

Almagro, A., Lin, S. H., and Tsay, Y. F. (2008). Characterization of the Arabidopsis nitrate transporter NRT1.6 reveals a role of nitrate in early embryo development. Plant Cell. 20, 3289-3299. doi: 10.1105/tpc.107.056788

Aoki, Y., Okamura, Y., Tadaka, S., Kinoshita, K., and Obayashi, T. (2016). ATTED-II in 2016: A plant co expression database towards lineage-specific co-expression. Plant Cell Physiol. 57:e5. doi: 10.1093/pcp/pcv165

Álvarez-Aragón, R., and Rodríguez-Navarro, A. (2017). Nitrate-dependent shoot sodium accumulation and osmotic functions of sodium in Arabidopsis under saline conditions. Plant J. 91, 208-219. doi: 10.1111/tpj.13556

Basile, A., Sorbo, S., Golia, B., Montanari, S., Castaldo-Cobianchi, R., and Esposito, S. (2011). Antioxidant activity in extracts of Leptodictyum riparium (Bryophyta), stressed by heavy metal, heat shock, and salinity. Plant Biosyst. 145, 77-80. doi: 10.1080/11263504.2010.509935

Beeckman, T., Przemeck, G. K., Stamatiou, G., Lau, R., Terryn, N., De Rycke, R., et al. (2002). Genetic complexity of cellulose synthase a gene function in Arabidopsis embryogenesis. Plant Physiol. 130, 1883-1893. doi: 10.1104/pp.102.010603

Bellincampi, D., Cervone, F., and Lionetti, V. (2014). Plant cell wall dynamics and wall-related susceptibility in plant-pathogen interactions. Front. Plant Sci. 5:228. doi: $10.3389 /$ fpls.2014.00228

Boursiac, Y., Chen, S., Luu, D. T., Sorieul, M., van den Dries, N., and Maurel, C. (2005). Early effects of salinity on water transport in Arabidopsis roots. Molecular and cellular features of aquaporin expression. Plant Physiol. 139, 790-805. doi: 10.1104/pp.105.065029

Cardi, M., Castiglia, D., Ferrara, M., Guerriero, G., Chiurazzi, M., and Esposito, S. (2015). The effects of salt stress cause a diversion of basal metabolism in barley roots: possible different roles for glucose-6-phosphate dehydrogenase isoforms. Plant Physiol. Biochem. 86, 44-54. doi: 10.1016/j.plaphy.2014. 11.001

Carpaneto, A., Boccaccio, A., Lagostena, L., Di Zanni, E., and ScholzStarke, J. (2017). The signaling lipid phosphatidylinositol-3,5-bisphosphate targets plant CLC-a anion/H+ activity. EMBO Rep. 18, 1110-1107. doi: $10.15252 / \mathrm{embr} .201643814$

Cobb, J. N., Declerck, G., Greenberg, A., Clark, R., and McCouch, S. (2013). Next-generation phenotyping: requirements and strategies for enhancing our understanding of genotype-phenotype relationships and its relevance to crop improvement. Theor. Appl. Genet. 126, 867-887. doi: 10.1007/s00122-013-2066-0

Curci, P. L., Aiese Cigliano, R., Zuluaga, D. L., Janni, M., Sanseverino, W., and Sonnante, G. (2017). Transcriptomic response of durum wheat to nitrogen starvation. Sci Rep. 7:1176. doi: 10.1038/s41598-017-01377-0

De Angeli, A., Monachello, D., Ephritikhine, G., Frachisse, J. M., Thomine, S., Gambale, F., et al. (2006). The nitrate/proton antiporter AtCLCa mediates nitrate accumulation in plant vacuoles. Nature 442, 939-942. doi: $10.1038 /$ nature 05013

Esposito, S. (2016). Nitrogen assimilation, abiotic stress and glucose-6phosphate dehydrogenase: the full circle of reductants. Plants 5:24. doi: 10.3390/plants5020024

Fan, X., Naz, M., Fan, X., Xuan, W., Miller, A. J., and Xu, G. (2017). Plant nitrate transporters: from gene function to application. J. Exp. Bot. 68, 2463-2475. doi: $10.1093 / \mathrm{jxb} / \mathrm{erx} 011$

Fernandes, J. C., García-Angulo, P., Goulao, L. F., Acebes, J. L., and Amâncio, S. (2013). Mineral stress_ affects the cell wall composition of grapevine (Vitis vinifera L.) callus. Plant Sci. 205-206, 111-120. doi: $10.1016 /$ j.plantsci.2013.01.013

\section{ACKNOWLEDGMENTS}

SE acknowledges funding by "Benessere dalle BioTecnologie: Nuovi Processi e Prodotti per la Nutraceutica, la Cosmeceutica e la Nutrizione umana (BenTeN)" by Regione Campania - D.R. $\mathrm{n}^{\circ} 199$ 26Oct2011; and $254 / 2011$.

Fernandes, J. C., Goulao, L. F., and Amâncio, S. (2016). Regulation of cell wall remodeling in grapevine (Vitis vinifera L.) callus under individual mineral stress deficiency. J. Plant Physiol. 190, 95-105. doi: 10.1016/j.jplph.2015. 10.007

Franciosini, A., Rymen, B., Shibata, M., Favero, D. S., and Sugimoto, K. (2017). Molecular networks orchestrating plant cell growth. Curr. Opin. Plant Biol. 35, 98-104. doi: 10.1016/j.pbi.2016.11.010

Fukuda, H. (2014). Plant Cell Wall Patterning and Cell Shape. Hoboken, NJ: Wiley.

Glass, A. D., Britto, D. T., Kaiser, B. N., Kinghorn, J. R., Kronzucker, H. J., Kumar, A., et al. (2002). The regulation of nitrate and ammonium transport systems in plants. J. Exp. Bot. 53, 855-864. doi: 10.1093/jexbot/53.370.855

Goel, P., and Singh, A. K. (2015). Abiotic stresses downregulate key genes involved in nitrogen uptake and assimilation in Brassica juncea L. PLoS ONE 10:e0143645. doi: 10.1371/journal.pone.0143645

Gojon, A., and Gaymard, F. (2010). Keeping nitrate in the roots: an unexpected requirement for cadmium tolerance in plants. J. Mol. Cell Biol. 2, 299-301. doi: 10.1093/jmcb/mjq019

Goubet, F., Misrahi, A., Park, S. K., Zhang, Z., Twell, D., and Dupree, P. (2003). AtCSLA7, a cellulose synthase-like putative glycosyltransferase, is important for pollen tube growth and embryogenesis in Arabidopsis. Plant Physiol. 131, 547-557. doi: 10.1104/pp.014555

Guerriero, G., Hausman, J. F., Strauss, J., Ertan, H., and Siddiqui, K. S. (2016). Lignocellulosic biomass: biosynthesis, degradation and industrial utilization. Eng. Life Sci. 16, 1-16. doi: 10.1002/elsc.201400196

Guerriero, G., Sergeant, K., and Hausman, J. F. (2014). Wood biosynthesis and typologies: a molecular rhapsody. Tree Physiol. 34, 839-855. doi: 10.1093/treephys/tpu031

Guo, F. Q., Young, J., and Crawford, N. M. (2003). The nitrate transporter AtNRT1.1 (CHL1) functions in stomatal opening and contributes to drought susceptibility in Arabidopsis. Plant Cell. 15, 107-117. doi: 10.1105/tpc.006312

Hong, M. J., Kim, D. Y., Lee, T. G., Jeon, W. B., and Seo, Y. W. (2010). Functional characterization of pectin methylesterase inhibitor (PMEI) in wheat. Genes Genet. Syst. 85, 97-106. doi: 10.1266/ggs.85.97

Hsu, P. K., and Tsay, Y. F. (2013). Two phloem nitrate transporters, NRT1.11 and NRT1.12, are important for redistributingxylem-borne nitrate to enhance plant growth. Plant Physiol. 163, 844-856. doi: 10.1104/pp.113. 226563

Hu, R., Zhu, Y., Wei, J., Chen, J., Shi, H., Shen, G., et al. (2017). Overexpression of PP2A-C5 that encodes the catalytic subunit 5 of protein phosphatase $2 \mathrm{~A}$ in Arabidopsis confers better root and shoot development under salt conditions. Plant Cell Environ. 40, 150-164. doi: 10.1111/pce.12837

Iovieno, P., Punzo, P., Guida, G., Mistretta, C., Van Oosten, M. J., Nurcato, R., et al. (2011). Transcriptomic changes drive physiological responses to progressive drought stress and rehydration in tomato. Front. Plant Sci. 7:371. doi: $10.3389 /$ fpls.2016.00371

Kiba, T., and Krapp, A. (2016). Plant nitrogen acquisition under low availability: regulation of uptake and root architecture. Plant Cell Physiol. 57, 707-714. doi: $10.1093 / \mathrm{pcp} / \mathrm{pcw} 052$

Landi, S., De Lillo, A., Nurcato, R., Grillo, S., and Esposito, S. (2017a). In-field study on traditional Italian tomato landraces: the constitutive activation of ROS scavenging machinery reduces effects of drought stress. Plant Physiol. Biochem. 118, 150-160. doi: 10.1016/j.plaphy.2017.06.011

Landi, S., Hausman, J. F., Guerriero, G., and Esposito, S. (2017b). Poaceae vs abiotic stress: focus on drought and salt stress, recent insights and perspectives. Front. Plant Sci. 8:1214. doi: 10.3389/fpls.2017.01214

Leucci, M. R., Lenucci, M. S., Piro, G., and Dalessandro, G. (2008). Water stress and cell wall polysaccharides in the apical root zone of wheat 
cultivars varying in drought tolerance. J. Plant Physiol. 165, 1168-1180. doi: 10.1016/j.jplph.2007.09.006

Li, G., Tillard, P., Gojon, A., and Maurel, C. (2016). Dual regulation of root hydraulic conductivity and plasma membrane aquaporins by plant nitrate accumulation and high-affinity nitrate transporter NRT2.1. Plant Cell Physiol. 57, 733-742. doi: 10.1093/pcp/pcw022

Li, X., Zhao, J., Walk, T. C., and Liao, H. (2014). Characterization of soybean $\beta$-expansin genes and their expression responses to symbiosis, nutrient deficiency and hormone treatment. Appl. Microbiol. Biotechnol. 98, 2805-2817. doi: $10.1007 / \mathrm{s} 00253-013-5240-\mathrm{z}$

Li, Y., Huang, J., Song, X., Zhang, Z., Jiang, Y., Zhu, Y., et al. (2017). An RNASeq transcriptome analysis revealing novel insights into aluminum tolerance and accumulation in tea plant. Planta 246, 91-103. doi: 10.1007/s00425-0172688-6

Ma, C., Haslbeck, M., Babujee, L., Jahn, O., and Reumann, S. (2006). Identification and characterization of a stress-inducible and a constitutive small heat-shock protein targeted to the matrix of plant peroxisomes. Plant Physiol. 141, 47-60. doi: 10.1104/pp.105.073841

Marín-Rodríguez, M. C., Orchard, J., and Seymour, G. B. (2002). Pectate lyases, cell wall degradation and fruit softening. J. Exp. Bot. 53, 2115-2119. doi: $10.1093 / \mathrm{jxb} /$ erfo89

Marowa, P., Ding, A., and Kong, Y. (2016). Expansins: roles in plant growth and potential applications in crop improvement. Plant Cell Rep. 35, 949-965. doi: 10.1007/s00299-016-1948-4

Minoia, S., Boualem, A., Marcel, F., Troadec, C., Quemener, B., Cellini, F., et al. (2015). Induced mutations in tomato SlExp1 alter cell wall metabolism and delay fruit softening. Plant Sci. 242, 1-8. doi: 10.1016/j.plantsci.2015. 07.001

Quan, X., Zeng, J., Ye, L., Chen, G., Han, Z., Munawar, J., et al. (2016). Transcriptome profiling analysis for two Tibetan wild barley genotypes in responses to low nitrogen. BMC Plant Biol. 16:30. doi: 10.1186/s12870-016-0721-8

Reynolds, M., and Tuberosa, R. (2008). Translational research impacting on crop productivity in drought-prone environments. Curr. Opin. Plant Biol. 11, 171-179. doi: 10.1016/j.pbi.2008.02.005

Ruggiero, A., Punzo, P., Landi, S., Costa, A., Van Ooosten, M., and Grillo, S. (2017). Improving plant water use efficiency through molecular genetics. Horticulturae 3:31. doi: 10.3390/horticulturae3020031
Sun, L., and Nocker, S. (2010). Analysis of promoter activity of members of the PECTATE LYASE-LIKE (PLL) gene family in cell separation in Arabidopsis. BMC Plant Biol. 10:152. doi: 10.1186/1471-2229-10-152

Tenhaken, R. (2015). Cell wall remodeling under abiotic stress. Front. Plant Sci. 5:771. doi: 10.3389/fpls.2014.00771

Van Oosten, M., Costa, A., Punzo, P., Landi, S., Ruggiero, A., Batelli, G., et al. (2016). "Genetics of drought stress tolerance in crop plants," in Drought Stress Tolerance in Plants Vol. 2, eds M. A. Hossain, S. H. Wani, S. Bhattachajee, D. Burrit, and L. Phan tran (Berlin: Springer), 39-70.

Weichert, A., Brinkmann, C., Komarova, N. Y., Dietrich, D., Thor, K., Meier, S., et al. (2012). AtPTR4 and AtPTR6 are differentially expressed, tonoplast-localized members of the peptide transporter/nitrate transporter 1 (PTR/NRT1) family. Planta 235, 311-323. doi: 10.1007/s00425-011$1508-7$

Yamaji, N., Huang, C. F., and Nagao, S. (2009). A zinc finger transcription factor ART1 regulates multiple genes implicated in aluminum tolerance in rice. Plant Cell 21, 3339-3349. doi: 10.1105/tpc.109.070771

Yang, W., Yoon, J., Choi, H., Fan, Y., Chen, R., and An, G. (2015). Transcriptome analysis of nitrogen-starvation-responsive genes in rice. BMC Plant Biol. 15:31. doi: 10.1186/s12870-015-0425-5

Zhao, W., Yang, X., Yu, H., Jiang, W., Sun, N., Liu, X., et al. (2015). RNA-Seq-based transcriptome profiling of early nitrogen deficiency response in cucumber seedlings provides new insight into the putative nitrogen regulatory network. Plant Cell Physiol. 56, 455-467. doi: 10.1093/pcp/pcu172

Zhou, J., Xie, J., Liao, H., and Wang, X. (2014). Overexpression of b-expansin gene GmEXPB2 improves phosphorus efficiency in soybean. Physiol. Plant. 150, 194-204. doi: 10.1111/ppl.12077

Conflict of Interest Statement: The authors declare that the research was conducted in the absence of any commercial or financial relationships that could be construed as a potential conflict of interest.

Copyright $\odot 2017$ Landi and Esposito. This is an open-access article distributed under the terms of the Creative Commons Attribution License (CC BY). The use, distribution or reproduction in other forums is permitted, provided the original author(s) or licensor are credited and that the original publication in this journal is cited, in accordance with accepted academic practice. No use, distribution or reproduction is permitted which does not comply with these terms. 